\title{
Antonio del Villar, retablista
}

\author{
DOLORES ÁlVAREz FERNÁNDEZ
}

Escultor y retablista de Redondela (Pontevedra), a quien consideramos como el mejor de cuantos trabajaron en la Diócesis de Tui (Pontevedra), durante la etapa barroca. Su actividad, se extendió a lo largo de más de tres décadas, 20, 30 y 40 del 1700, con un número no despreciable de retablos y una cantidad aún mayor de esculturas.

De su obra se consevan ejemplares suficientes y de entidad tal, que no dejan lugar a dudas sobre su maestría.

Muy pocas noticias tenemos, de momento, sobre su persona y vida privada, asi como de su formación artística. No obstante en ese empeño y búsqueda estamos todavía, a pesar de ser conscientes de que la quema de los archivos parroquiales de Redondela, por parte de los franceses, constituye todo un problema, lamentablemente insalvable, para el logro de tal objetivo.

Sabemos, sin embargo, que en 1724 compra una casa a Inés Martínez, viuda:

... para enttodo tiempo de siempre jamas vende y da en venta por juro y señorio de heredad a Antonio del Villar vezino de dha Villa vieja queesta presente y compra para el su muger e hijos y herederos la cassa terreña consu corral que esta ttejada sita en dha Villa vieja donde sale con su puerta a la calle [...] por precio y quantia de veinte y cinco Ducados en moneda de vellon de once rreales cada uno y de attruinta y quatro mrvs cada rreal que ei dho Antonio del Villar dio y entrego a Ines Martinez en moneda de plata y vellon...'

Este artista, de alguna manera, se implicaba también en los asuntos del campo, tal vez por una cuestión simple y ilana de manutención o de 
proporcionarse una mayor economía. Con todo, podemos deducir que su posición debía de ser desahogada, a juzgar por el número de retablos que ejecutó (todos de una cierta envergadura), en algún caso, como tendremos ocasión de comprobar más adelante, en puja con escultores de gran fama y prestigio como Miguel de Romay que trabajaba en Santiago de Compostela al lado de grandes arquitectos como Fernando de Casas y Simón Rodríguez.

Así en abril de 1727 se protocoliza una escritura de arriendo por:

Don Diego de Araujo Ozores y Sotomaior Abbad y cura propio desta feligresia de Santa Maria de Reboreda por virtud desta cedula firmada mia doy en arriendo al Rexidor Joseph Cura Cornexo vezino dela villa de Redondela = y a Antonio del Villar vezino de Villa Viexa y a Roque Bouzon vezino desta feligresia a todos tres es a saver el lugar de Revoreda y el lugar de Asnalle pertenecientes a mi beneficio, todos los diezmos de frutos, que coxieren y labraren los vezinos de dhos dos lugares assi de pan y todo genero de granos, vino, lana, diezmos y mas derechuras, que por razon de diezmo me deven pagar sin reservar para mi mas que la mitad dela paja triga, que se cogiere en dho diezmo, todo lo qual le arriendo en la conformidad que ba referido por tiempo y espacio de tres años enteros, tres frutos alzados y cogidos, que empiezan a correr y contarse desde el dia de san Juan veinte y quatro de junio deste pressente año de mill settezientos y veinte y siete y fenezera el mismo dia veinte y quatro de junio del año que vendra de mill settezientos y treinta, que fenecen dhos tres años; y por cada uno dellos me han de dar y pagar tres mill nuevecientos reales de vellon moneda corriente en este Reyno de Galicia puestos y pagos en mi cassa en esta dha feligresia en dos plazos, la mitad dellos por todo frebrero del año que vendra de mill setezientos veinte $y$ ocho y la otra mitad por todo septiembre de dho año y en esta forma correran los plazos de los otros dos años consecutivos, sin descuento alguno...

Como retablista, se caracteriza por: el dominio de las masas, con plantas cóncavas, juegos de luces, con perspectivas y contrastes que redundan en la consecución de un mayor movimiento; la decoración naturalista: tallos, hojas y flores de cuidadosa elaboración y un amplio abanico de diseño en las cartelas que distribuye en las claves de las hornacinas. Una constante suya es permanecer siempre fiel a la idea de la potenciación máxima de la calle central adelantándola, flanqueándola con soportes duplicados ( de los cuales utiliza indistintamente la salomónica y el estípite, solos o combinados) pero sobre todo haciéndola discurrir desde el banco al remate del retablo sin solución de continuidad, sin que, ni entablamento ni cornisa alguna, rompa esa sucesión de hornacinas, expositores o relieves que allí se disponen.

Como imaginero, sus figuras son movidas, abiertas, de expresiones apasionadas unas veces, serenas otras muchas. Las telas de ondulantes 
y suaves pliegues son tratadas con esmero y la "puesta en escena" se lleva, en algún caso, (como en la Anunciación de las Madres Dominicas de Baiona) al límite, en la utilización de efectos escenográficos.

Además de las esculturas que forman parte de los retablos, realiza otras muchas imágenes, entre ellas un Cristo crucificado para la iglesia de Viliavieja, para la de Santiago de Borbén diversas obras, según consta en las cuentas de fábrica de la misma:

3 de agosto de 1725 trescientos noventa reales que entrego a Antonio del Villar por quenta de los retablos, mas 319 reales y medio que dio al dho Villar por razon de dhos retablos.

28 de julio de 1740 quatrocientos quince reales que costo la imagen de Santiago mas seis reales a los que fueron a buscar a Redondela.

28 de agosto de 1749 doscientos reales de vellon que llevo a Antonio del Villar por hacer San Francisco Javier y San Ramon.

29 de julio de 1752 ciento sesenta reales que llevo a Antonio del Villar por dos imagenes de San Benito y San Bernardo.

30 de julio del 1753 doscientos quarenta reales que se dieron a Antonio del Villar a quenta de las imagenes de San Pedro y San Juan que esta haciendo?

A continuación analizamos los retablos conservados, que son todos ellos, así lo creemos, obras de gran calidad: el de la Expectación de la Catedral de Tui, de la Colegiata de Baiona, de Santa María de Reboreda, de Santa Liberata de Baiona, de Santo Domingo de Tui, de las Madres Dominicas de Baiona y el de la Capilla de la Misericordia igualmente de esta localidad.

RETABLO DE LA EXPECTACIÓN. CATEDRAL DE TUI. 1722. TUI

\section{Descripción}

Monumental retablo de planta cóncava. Su estructura formal está compuesta por un alto banco cajeado, todo él de talla, en el que destacan sobre todo los frentes de los netos y los paneles centrales de los entrepaños, en donde un aparatoso motivo vegetal encierra una cabecita de querube.

2. Iglesias Almeida, Ernesto, Arte y Artistas en la Antigua Diócesis de Tui. Tui. 1989, pág. 114. 


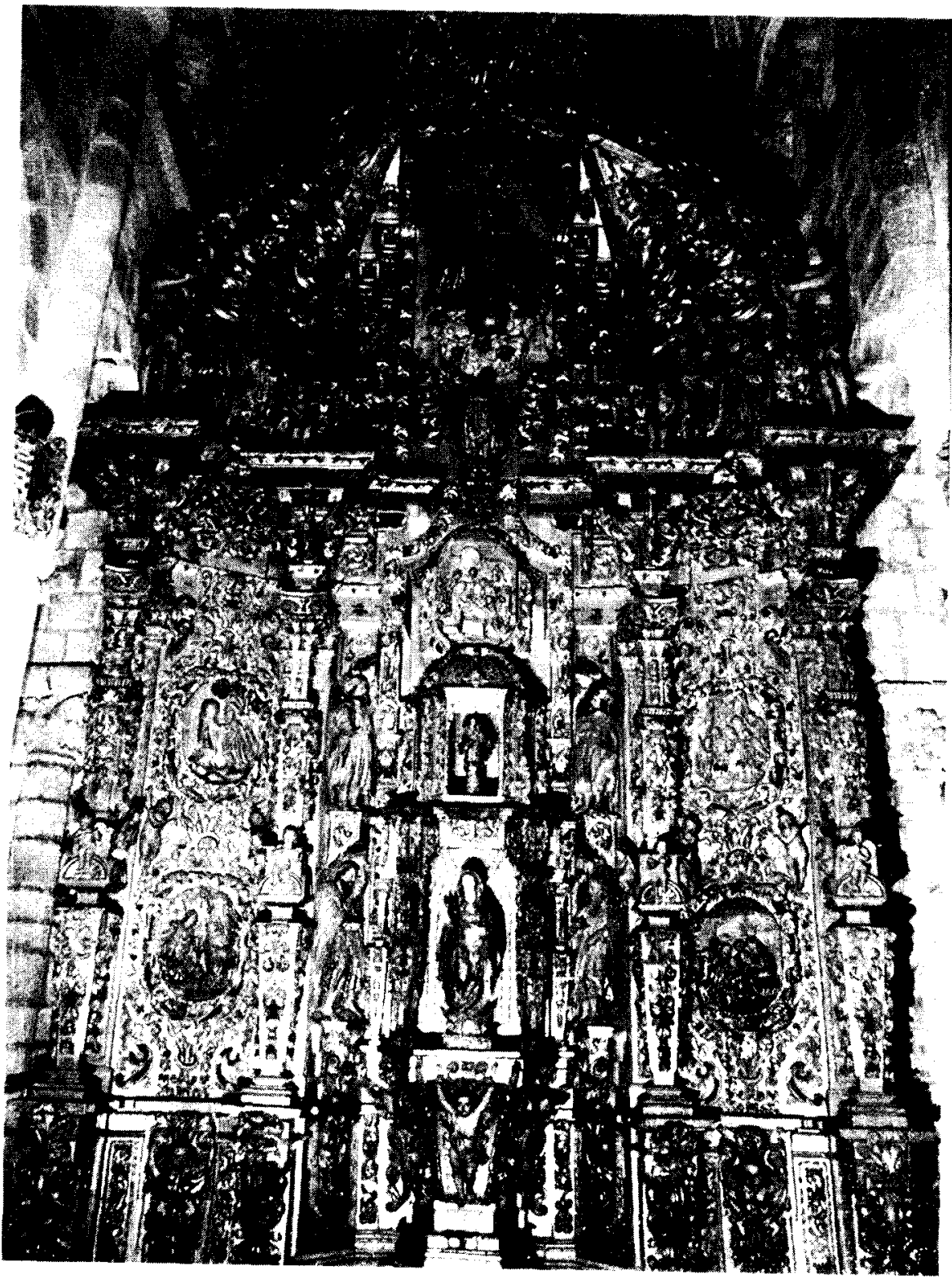

Fig. 1. Expectación catedral de Tui. 
Lleva un único cuerpo de elevadas proporciones porque el sitio donde se ubica, así lo exige. Se articula en tres calles delimitadas por cuatro estípites de complicado diseño (en su necesidad de hacerse gigantes, para cubrir altura), a los que se incorporan angelillos músicos.

La calle central la ocupa el expositor que muestra a la Virgen titular (Preñada, de la Expectación, o de la O) que se eleva sobre gran pedestal de planta hexagonal, con ángeles telamones en cada frente, cubiertos solamente por una banda; los soportes son dos pares de estípites diferentes. Sobre él otro, más pequeño, con el frente en arco de medio punto y los laterales adintelados que alberga la imagen de la Virgen del Pilar. A ambos lados de los dos camarines, en sitiales remarcados por peanas y veneras se colocan cuatro personajes, de los que reconocemos al rey David por su corona y a San Joaquín por el turbante.

Las calles laterales vienen ocupadas por dos filas de medallones, con relieves de los Misterios Gozosos, enmarcados con tupida vegetación que cubre completamente los tableros. Anunciación y Visitación, del lado del Evangelio, la Adoración de los Reyes y Presentación, en el de la Epístola. El misterio del Nacimiento por su especial importancia en el tema iconográfico que se trata en el retablo, se coloca en el eje longitudinal, centrando física y simbológicamente toda la orquestación iconográfica. Se trata de escenas afables y comunicativas; la fuerza de su volumen, las posiciones naturales y desenvueltas, las formas carnosas, expresivas, al tiempo que una gracia sonriente y amable, a la que no es ajeno un detallismo narrativo, pone un tono de intimidad familiar en los episodios.

El entablamento alcanza aquí una entidad considerable; ornamentando el friso con ovas, modillones y cartelas en los intercolumnios. Por su parte, la cornisa presenta un gran vuelo debido a que sobre ella se colocan seis profetas, en grupos de tres, precedidos por ángeles cubiertos con bandas y Adán y Eva colocados a plomo, sobre los ejes de los soportes exteriores.

El ático se resuelve en cascarón con su cerco de talla muy realzada. La parte central la ocupa una caja de avance con bovedilla de medio cañón y flanqueada a ambos lados por un par de estípites que se alzan sobre altos macizos palmeados. Encima de dicha caja una bella representación de la Santísima Trinidad.

Se corona el retablo con un remate de calada labor, en el que se destaca el anagrama de María.

A los lados, en los pilares de las naves, figuran los escudos con las armas del obispo D. Fernando Ignacio de Arango y Queipo, patrocinador de la obra. 


\section{Datos sobre su construcción}

En el Acta de Acuerdos Capitulares del Cabildo de Tui de fecha 23 de febrero de 1722 se lee;

"En este Cavdo seacordo seotorgue la escritura de concierto del retablo del altar de la preñada, desta santa iglesia, que esta consertado en la cantidad de veinte y quatro mill quinientos rls. de vellon con Antonio del Villar maestro de Arquitectura, vecino de la villa de Redondela..."

\section{El 29 de abril de 1727 se protocolizó la escritura de dorado y estofado;}

"Juan Fagundes de oficio pintor vezino de la ciudad de Braga (en el reino de Portugal) en la cantidad de 24.000 rls. de vellon, fabricado de poco e por eso a esta parte todo de oro el mas vien batido y de mas subidos quilates, menos un pedestal que se halla de cabteria, que se a de dar un color jazpeado a oleo para su ornamentación el pedestal de madera, tamvien a de ser dorado todo el, con sus fondos, y en los fondos que se allaren en el de color que le diere enzima del oro, a de ser un verde estilado sin que entre otro color alguno, menos que si se allaren entre la talla de el algunas flores, esas las estofara el rezivimiento del Camerin de la mesma suerte sin que aia bariedad de colores, mas que la referida, solo que los niños que le rreciven an de ser encarnados al pinzel, que es lo natural de las encarnaziones y de la misma suerte las figuras o Angeles que se allaren desnudos en dho Retablo: los estipites que se allan en dho Retablo con su Cernisamiento y dos tableros que se compone de los misterios gozosos, historia de medio rrelieve dhas historias y pilastras de los estipites y fondos que en todo ello se hallaren se a de dar el color berde estofado como queda rreferido, menos en los estipites que por bariar de color en los apallones que tienen como junquillos y quarta bosel, se dara un color de carmin enzima del oro: el cuerpo conforme se alla de la mesma suerte menos el fondo de dho Camerin con el casco de a dentro de la media naranja, que excusa dorarse, sino darla un color que sea dezente con su barniz por enzima para su manutención, todo el cuerpo prinzipal rreferido a de ser en la forma que ba dho juntamente con quatro Prophetas que se hallan arrimados al camarin que an de ser estofados con los colores correspondientes que pidiere cada uno como tanvien las flores de talle que se ellaren en utio cuerpo an de ser estofadas, conforme cada una señalase su figura = el segundo Cuerpo poque se compone de su Pedestal quatro estipites, y la formazion de el de un medio Casqueron con su Cerdra de talla mui rrealzada y su cartorcha que tiene por rremate. $y$ en medio de dho medio cuerpo entra una caxa de abanze con su medio cañon en que esta rrepresentada la historia de la Santisima Trinidad con su trono de serafines a los pies y los fondos desta caxa deven finxir en ella unos reflexos de gloria. Los siete Profetas y nuestros primeros padres, los profetas seran estofados segun los colores que cada uno pidiese y nuestros Padres Adan y Eva al pinzel, y los fondos deste medio Cuerpo como el Cuerpo principal de avajo, an de ser del color berde estilado encima del oro como ba rreferido, y los estipites y flores, segun los demas que ban nombrados..." 
Fuentes documentales y bibliográficas

\author{
A.C.T. Acuerdos Capitulares. T XII. Fol. 377 vito. \\ A.C.T., esno. Juan de Insua y Valdivieso. Año 1728 (7). Fol. 95. \\ IGLESIAS ALMEIDA, Ernesto; op. cit. Pág. 113-159.
}

RETABLO MAYOR DE LA COLEGIATA DE BAIONA. 1726. MIÑOR

\title{
Descripción
}

Presenta una planta movida con ménsulas destacadas y la calle central adelantada. Consta de banco, cuerpo principal dividido en tres calles por estípites (que se duplican en el centro) y cerrando el conjunto, el ático. Cumpliendo su misión de limitación de ambos espacios, se dispone un entablamento quebrado que desaparece en su parte central, constituyendo el marco del hermoso relieve que allí se dispone con la escena de la Anunciación.

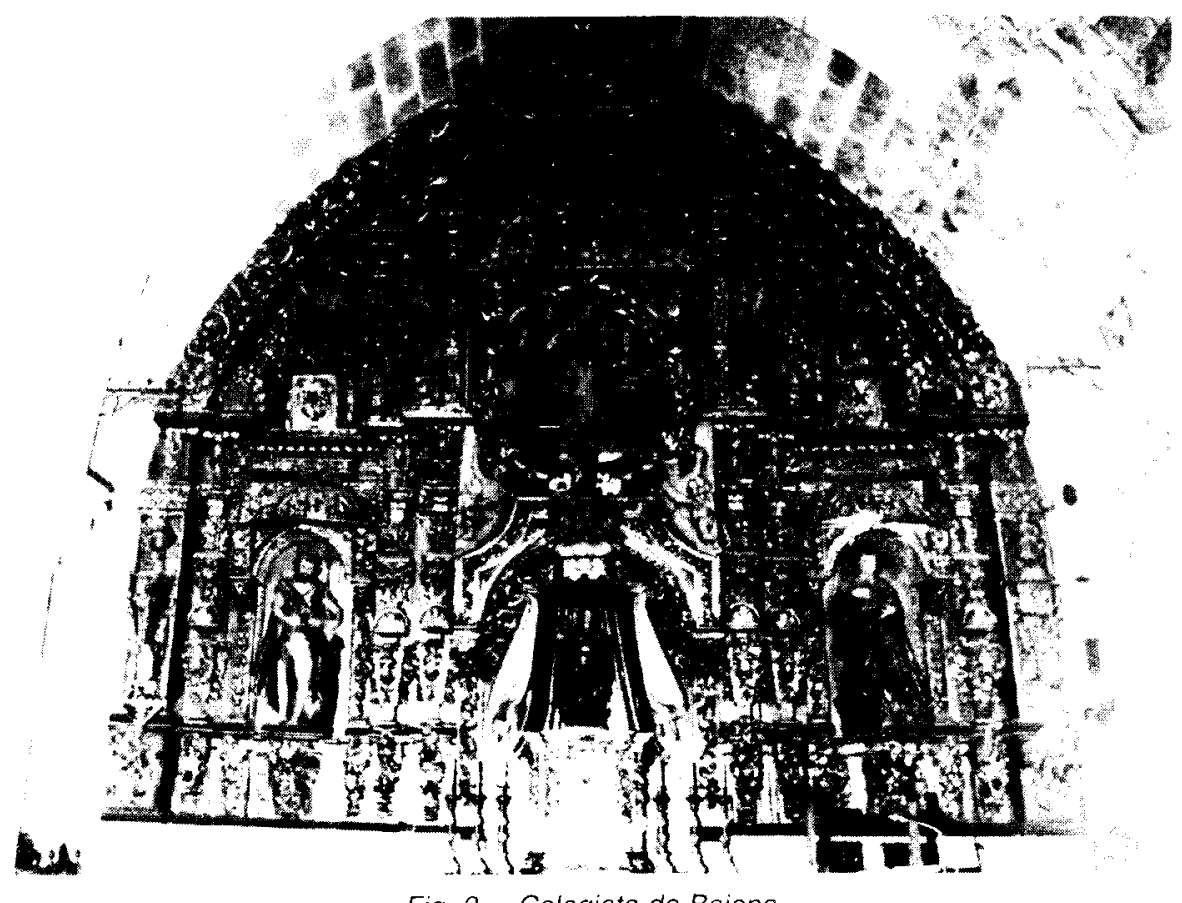

Fig. 2. Colegiata de Baiona 
En las calles laterales las hornacinas se rematan en cuartos de esfera decoradas con primoroso calado. Reciben las imágenes de los Santos Juanes (San Juan Bautista y San Juan Evangelista).

Pero indudablemente, es la calle central la que atrae toda nuestra atención. Por un lado, su adelantamiento respecto al resto de la superficie, que produce una sensación de dinamismo y profundidad, realzado por la propia hornacina central; por otro, su discurrir contínuo y finalmente por la iconografía que presenta.

\section{Datos sobre su construcción}

El 29 de marzo de 1726 se protocoliza la escritura de obra entre los representantes del Justicia y Regimiento de la villa:

"... y de la otra Antonio del/ Villar Maestro de escultura y arquitectura y vecino dela villa vieja de Redondela y difjeron que porquanto por decreto de sess de Henero deste presente año que selebraron deuna/ conformidad havian acordado se hiciese en la lglesia Colegiata desta dha villal un retablo porla falta que ttenia del y attendiendo aque dha Iglesia no ttenia/ ni tiene fabrica alguna para poderle hazer y para ello mandaron se fisasen editos/ en las villas y ziudades deste reino para que los maestros descultura y arquite/tos que quisieran hazer postura al dho retablo concurriesen cadauno con su mapa/ o planta para que enconcurso dellos esta villa eligiese la mas acomodada y de mejor fabri/ca al sittio de la Capilla maior de dha Iglesia Colegiata y que en su conformidad se halvian despachado dhos editos y asignado el rremate desusposturas para el dia veintel y seis deste presente mes y con efecto han hecho postura a dho retablo Francisco Alonso/ vecino dela villa del Porriño Miguel de Romay dela ziudad de Santiago y Antonio del/ Villar dela villa vieja de Redondela y concurriendo para dho remate en esta villal en dho dia veinte $y$ seis entre los dhos Antonio del Villar $y$ Francisco Alonso hizieron diferentes/ mejoras y vajas a las dhas posturas $y$ por ultimo en la que hizo el dho Antonio del Villarl de ocho mil reales de veIlon serremato en el dha obra por dha cantidad el dia deayer."

Figura también el establecimiento de fianzas, como dictaba la constumbre. Los 8.000 reales se pagarian en los tres plazos habituales y finalmente una condición no muy habitual: «... que a de admitir por oficiales para la fabrica de dha obral al dho Francisco Alonso y a Diego de otero vecino desta villa con el salario que a ca/da uno correspondiese..."

\section{Fuentes documentales y biliográficas}

A.H.P.P. esno. Baltasar Pablo de Mendoza. Prot. 2.576 (2), año 1726 , fol. 6 . 
RETABLO MAYOR DE SANTA MARIA DE REBOREDA. 1730-35. REDONDELA

\section{Descripción}

Se trata de un retablo que, partiendo de un zócalo de piedra, despliega sus más que moderadas dimensiones, organizado en banco, un cuerpo de tres calles y ático.

La predela presenta los frontales de los netos decorados con hojarasca y palmas $y$, en el centro, el sagrario de planta cuadrada, que avanzando

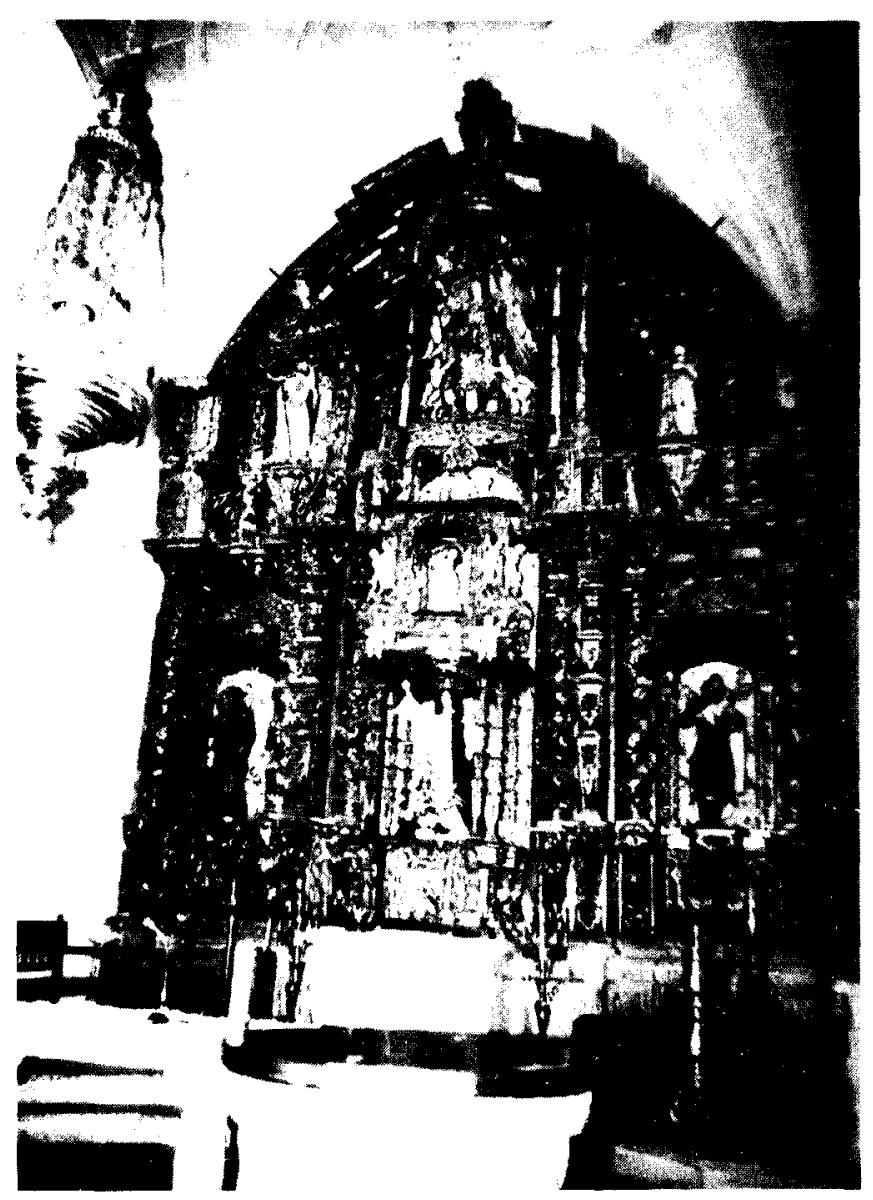

Fig. 3. Santa Maria de Reboreda 
hacia el espectador, le muestra su puerta ornamentada con un relieve representando el pasaje bíblico del sacrificio de Abraham.

El cuerpo principal delimita sus calles por seis columnas salomónicas de cuatro espiras, diferenciándose las centrales por recubrirse con flores mientras que las demás presentan ramas en sus gargantas y de los senos cuelgan jugosos racimos. En los intercolumnios centrales se tallan estipites.

Una imagen de la Virgen titular, procesional de vestir, ocupa el lugar preferencial en un expositor que no es sino el primero de los tres, todos ellos cupulados, con los que nos encontramos, a medida que ascendemos en su contemplación.

El primero, decíamos, enteramente abierto, se sostiene por tres pares de estípites y lleva dos angelillos sentados sobre el eje de los primeros. A continuación otro pequeño expositor, ornamentado en su base con penachos en cuyos rizados extremos se apoyan cuatro niños que simulan sostener, con un brazo alzado, los capiteles; finalmente el tercero, ya en el ático, enmarcado por machones y flanqueado por dos pares de estípites, alberga la representación de la Asunción y Coronación de María. Ayudada en el primer caso por un corro de ángeles y coronada por la Santísima Trinidad.

En las calles laterales del primer cuerpo se abren hornacinas cupuladas en donde se colocan las imágenes de San José, en el lado de la Epístola y San Roque, en el del Evangelio.

El entablamento, reducido a la mínima expresión en su delimitación de espacios, sigue las sinuosidades de los ejes de los soportes.

Un rebanco de talla, da paso al ático tripartito en el que los compartimentos laterales se ocupan por destacadas cajas con anchos marcos cuadrilongos y rematadas por densos motivos vegetales. La de la derecha alberga a San Ramón Nonato y la de la izquierda a San Juan Bautista.

Este último espacio se cierra en arco apuntado, plegándose a la forma de la bóveda con un borde de ovas que, al decorar también el entablamento, contornea totalmente el ático y otra banda más volada, que se quiebra en el centro para dejar paso a un pequeño florón que marca la clave.

A ambos lados figuran las armas de la casa de Reboreda, los Prego y Montaos, sus patrocinadores, apoyados sobre macizos extremos del rebanco. 
Datos sobe su construcción

En el año 1736 se entabla un pleito sobre el Patronato y Presentación del Beneficio Curado de esta feligresía entre el Doctor D. Manuel de Noriega y Mier y D. Bernardino Pereyra y Prego y su hermano D. Balthasar Ramón Pereyro y Prego. En las declaraciones del mismo figura;

«D. Diego de Araujo al reedificar la iglesia de Reboreda, como el retablo de ella, y a su costa, como pensión de los patronos, cuyo retablo habia hecho de su orden uno de estos testigos que lo refiere..."

Por esta referencia documental sabemos que el autor de esta magnífica obra fue el escultor de Redondela Antonio del Villar.

El retablo está aún sin dorar en 1745 cuando se concluye el pleito.

Fuentes documentales y bibliográficas

Archivo Parroquial de Santa María de Reboreda. Pleito.

RETABLO DE LA CAPILLA DE SANTA LIBERATA. BAIONA. 1738. MIÑOR

\section{Descripción}

La distribución del espacio sufre en este retablo importantes modificaciones, al darse la extraordinaria circunstancia de ser nueve las santas que se quieren colocar en el centro (la Titular, Santa Liberata y sus ocho hermanas, Santa Germana, Santa Quiteria, Santa Marina, Santa Ginebra, Santa Basilisa, Santa Marciana, Sarta Eufemia y Santa Victoria ) a las que aún hay que añadir la nodriza, Santa Sila. Es por ello que la calle central no sólo ccupa la mayor parie del primer cuerpo, reduciendo las laterales a una mínima expresión, sino que ademas invade generosamente el ático, dejando en los extremos apenas lugar para dos pequeños registros, de arco de medio punto, que más bien parecen continuación de las estrechas calles laterales y que recogen las esculturas de Santa Bárbara y Santa Apolonia.

Por otra parte, el decidido adelantamiento de la zona central modifica igualmente las líneas direccionales del banco, creando planos biselados en donde se colocan dos relieves que, junto con los otros dos situados en los paneles extremos nos relatan episodios de la vida de las santas. 


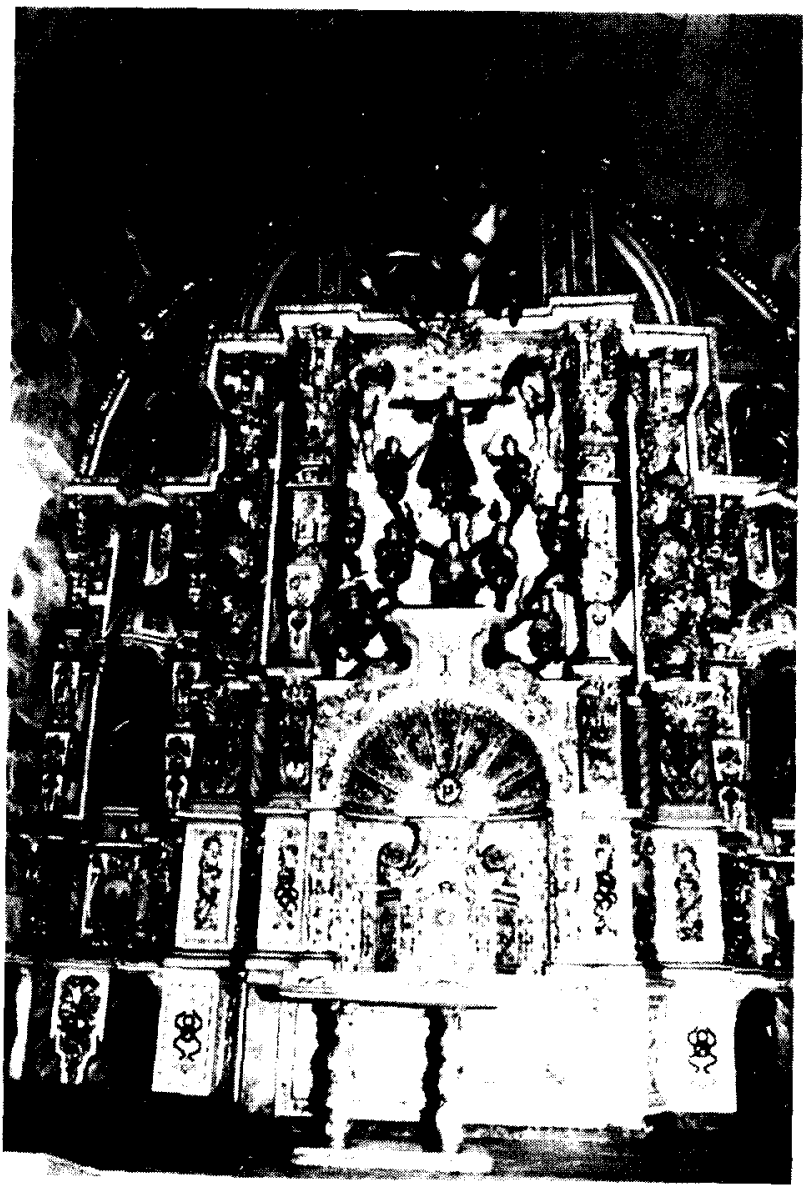

Fig. 3. Santa Liberata de Baiona.

El sagrario se coloca en el interior de un amplio arcosolio de intradós plementado y enjutas decoradas con cintas.

Las hornacinas laterales son planas, lo que hace imprescindible el uso de resaltadas peanas para recibir la imaginería, San Pedro y San Pablo. Se coronan con cuartos de esfera asentadas sobre tamborcillos.

El espacio central del ático se centra por dobles machones y arbotantes laterales. Presenta el grupo escultórico de Santiago Matamoros, cuyas figuras, el caballo y las inestables posturas de los infieles les obligan a salirse del marco de una forma absoluta.

En la clave del arco que cierra el retablo, se asienta el escudo de Armas de la villa de Baiona, que costeó la obra. 
Es evidente, en este ejemplar un cambio en la decoración, en cuanto que se hace mas esquemática y estilizada, con la utilización sobre todo de flores y lazos, enmarcados por líneas geométricas.

\section{DATOS SOBRE SU CONSTRUCCIÓN}

El 16 de agosto de 1738, se celebraron en Baiona las posturas: Antonio del Villar en 16.000 rls. de vellón; Francisco Alonso de Porriño en 15.000 rls.; Agustín Correa, vecino de Baiona en 14.500; Antonio del Villar rebajó entonces a 14.000; Agustín Correa rebajó a 13.000 reales; de nuevo Antonio del Villar a 12.000 , ya no hubo mejor postor, y a las seis y media de la tarde se remató en el escultor redondelano con las condiciones siguientes;

«... Primeramente que dho rretablo se a de aser porla planta y disenio queba firmado/ y seade conponer de seis estipites, dos colunas salomonicas/ vestidas al estilo nuebo con sus papiras o pedestales quelas resiven, con los yntermidios/ que hazen figura de obalos para recibir las ystorias que dhos senores/ elixieron, como las dos caxas de costado que ttienen daltto seis quartas y media/ en donde sean de poner dos estatuas launa de San Pedro y la otra de/ Sanpablo, y se componen dhas caxas de Abanze consu cornisamiento y me/dio cascaron, donde queda, devaxo del arquitrabe que corresponde, a la corinisa que rrecive el deposito que tiene de altura once quartas y media, se componef en el un deposito para recivir anuestro Amo y encima del, otro segundo/ deposito con una Arca para recivir la reliquia de Santa Liverata y ent zima del se compone un medio cascaron para recivir anuestro Amo patente/ el dia que quisieran ponerle, que en el pueda aver cortina para correr/la alaora devida el frontis, se compone en la disposicion que en/seña la planta y en el se allan quatro Angeles desnudos que cada uno lleivara su cornicopia para poner luzes, y en el despidiente de dho frontis/ enttra el tronco para rrezivir las ocho Hermanas con Santa Liberata/ que esta adeser de cinco quartas y media y las ermanas del tamañol queles corresponde de medio cuerpo y al pie de dho tronco a de estar el/ ama, mirando las santas $y$ las ymagen de Santa Liverata a deser/ gueca y portatil para andar en prosecion, que se a de quittar y poner y fi/xarla con dos tornillos; y la que sealla en dha capilla, en el dial dela funzion sea de poner en el sitio dela quese hiziese travajandol en ella lo nezesario para dho fin y dha caxa que rrezive dho Arboll se compone de un arco de medio punto; su cornisa y dos angelottes que le rrecilven de abanze y en el medio una cartonela con la caveza deun/ serafin en medio y en el cuerpo prinzipal de dha obra que ba referida/ se compone con las dos colunas y estipites que ban dhos con la con/dizion que las pilastras della, an deser obradas y asocaladas como en/seña la planta, el pedestal de la Capilla, astta el alto del alttar comu / tanvanillo que divide los dos leones con su frontal echa de talla en medio/ y enzima de dha cornisa/ an de entrar en cada estipite y columna sut angel centrados a la corresepondenzia de dha obra que son ocho piezas que/ llevara cada una en la mano su corona y palma = el segundo cuerpo/ se compone de medio punto 
y enel se allan tres caxas, las dos de costa/do y altura debara, y enla una, a de estar la estatua de Santa Polonial y en la otra la de Santa barbara y en la Casa del medio que ttiene de Altural seis quartas y media y de ancho ottro tantto, y enella a de estar la esta/tua de Santiago de Acavallo, con tres moros o cuatro de correspon/dencia dedha estatua y la caxa la acompañan, dos angeles de a bara del altto que esttan manuteniendo el escudo de Armas deestta villa y la caxa/ se compone detres pilastrones que bienen haziendo suabanze conla cer/cha y lavor que enella sealla de cada costado con dos fontanchas quela/ guarnezen y dha cercha ade ser acodillada $y$ encadenada, que aga unal misma piesa que salga desde la pared con el Abanze corresepondiente a dho/ planttado añadiendose ael un pie mas desu salida que es una terzia/ castellana, elqual ba señalando en dho plantado, su salida y una/ estrella quele enseña; y juntamenye sea de hazer un Marco de tallal en distanzias con el para el frontal que corresponda a dha obra, y asilmismo una ymagen de Christo de una terzia para el altar en donde se dize/ misa queadeser portatil; y dha obra, a deser toda ella de madera del castaño bravo y manso, y no ade enttrar madera alguna de pino ni otro ge/nero asimismo es condizion que la dha obra, a de ser conduzida, a dha capilla por quental del expresado Antonio del Villar y la a de dar echa puesta $y /$ sentada para el dia de S. Juan del año proximo que viene de mil se/ttecientos treinta y nuebe, y las esttadas para sentar dha obra, an de ser/ por quenttas delos caudales de dha Santa y deesta villa;"

Los 12.000 reales en que se remató la obra se le pagarian en tres partes: la primera en el momento, la segunda el 15 de enero de 1739 y la tercera después de terminada y montada la obra.

El plazo de tiempo dado, debió cumplirse, puesto que en julio del citado año 1739, está terminado como se demuestra por un acuerdo del Ayuntamiento de 21 del citado mes;

"... acordaron que por quanto se a echo el rettablo para la gloriosa Santa liberata colocar su reliquia en su propia capilla que tiene junto a la Iglesia Colegial desta villa... ${ }^{3}$,

No se esperaron más que tres años para dorarlo y pintarlo. El 23 de octubre de 1742 se lleva a cabo la escritura de contrato entre los representantes del "Justizia y Reximiento" de la villa de Baiona y Esteban da Silva, vecino de Braga (Portugal) y Alejandro Dominguez, vecino de Tui, maestros del arte de pintura;

"... y dixeron que por quanto antes deaora se allan/ convenidos y ajusiados con sus mercedes dha Justizia y Reximiento/ los rreferidos maestros de

\footnotetext{
Cameselle Bastos, Domingo; Capilla de Santa Liberata. Bayona la Real.
} 
pinttar el rettablo dela martir/ santa liberata Patrona desta villa segun y en la conformi/dad que a lo adelante yra expresado y quepara ello sean de/ pagar por su travajo nuebe mill rreales vellon. Los quatro mill/ los da por via de limosna a la Santa D. Plazido Correa Arzidianol de Miñor, Canonigo y Dignidad en la Santa Iglesia Catedrall dela ziudad de Tuy y los cinco mil rrestantes estta villa jun/tamente de afrontar las esttadas nezesarias para el fin de pintarl dho rettablo; cuias calidades y condiziones son las siguientes: 10 primero que los dhos maesttros aian de pinttar tho rettablo/ de la martir santa liberata, segun y en la conformidad quese alla/ el rettablo de Nuestra Señora la preñada u ottro mejor que aial dentro de dha Catthedral de la rreferida ciudad de Tuy, po/niendole las pintturas segun y conforme seallan el rreferido/ rettablo de Nuestra Señora la preñada, $u$ ottro mejor que aia en dhal Cathedral de Tuy. sin que, en ello aian de ponerse de mas ni de/ menos las rreferidas pinturas, lo segundo de que lo aian de/ pintar y ponerlo en perfezion denttro de quatro meses/ que pinzipiaran a correr desde primero de noviembre de estel presentte año y fenecera en febrero que viene del año de mil setecientos quarenta y ttres para lo qual lean de dar y en/ttregar dos mil ris vellon para el pinzipio de dha pintura/ y lo resttante al cumplimiento de los nuebe mill selean de en/ttregar y pagar asi quese finalize dha obra; con la con/dizion que primero se ha de rreconozer con perittos que en/ttienda dela facultad de pintura."

Fuentes documentales y bibliográficas

A.H.P.P., esno. Baltasar Pablo de Mendoza. Prot. 2.577(6). Año 1738, fol. 40 .

A.H.P.P., esno. Benito Antonio Román Fernández. Prot 2.807(1). Año 1742 , fol. 4

RETABLO MAYOR DE LA IGLESIA DE SANTO DOMINGO DE TUI.

1744. TUI

\section{Descripción}

De considerables proporciones, puesto que se eleva hasta la clave de la bóveda de la capilla mayor, es uno de los escasísimos ejemplares en la zona, que presentan dos cuerpos, en lugar de uno, además, claro está, de banco y ático.

De planta ochavada diferenciada en tres partes, se cierran resolviendo su ático en cascarón, de tres sectores correspondientes a las calles, que al hacer coincidir prácticamente los rampantes con los ejes de los soportes y 
la rosca del arco de cierre con los remates laterales, presta al conjunto una inusitada uniformidad vertical del espacio; que se potencia, además, por la colocación en ángulo de las hornacinas que acogen a Santos de la Orden: San Telmo, San Jacinto, Santo Tomás, Santa Catalina y Santa Rosa.

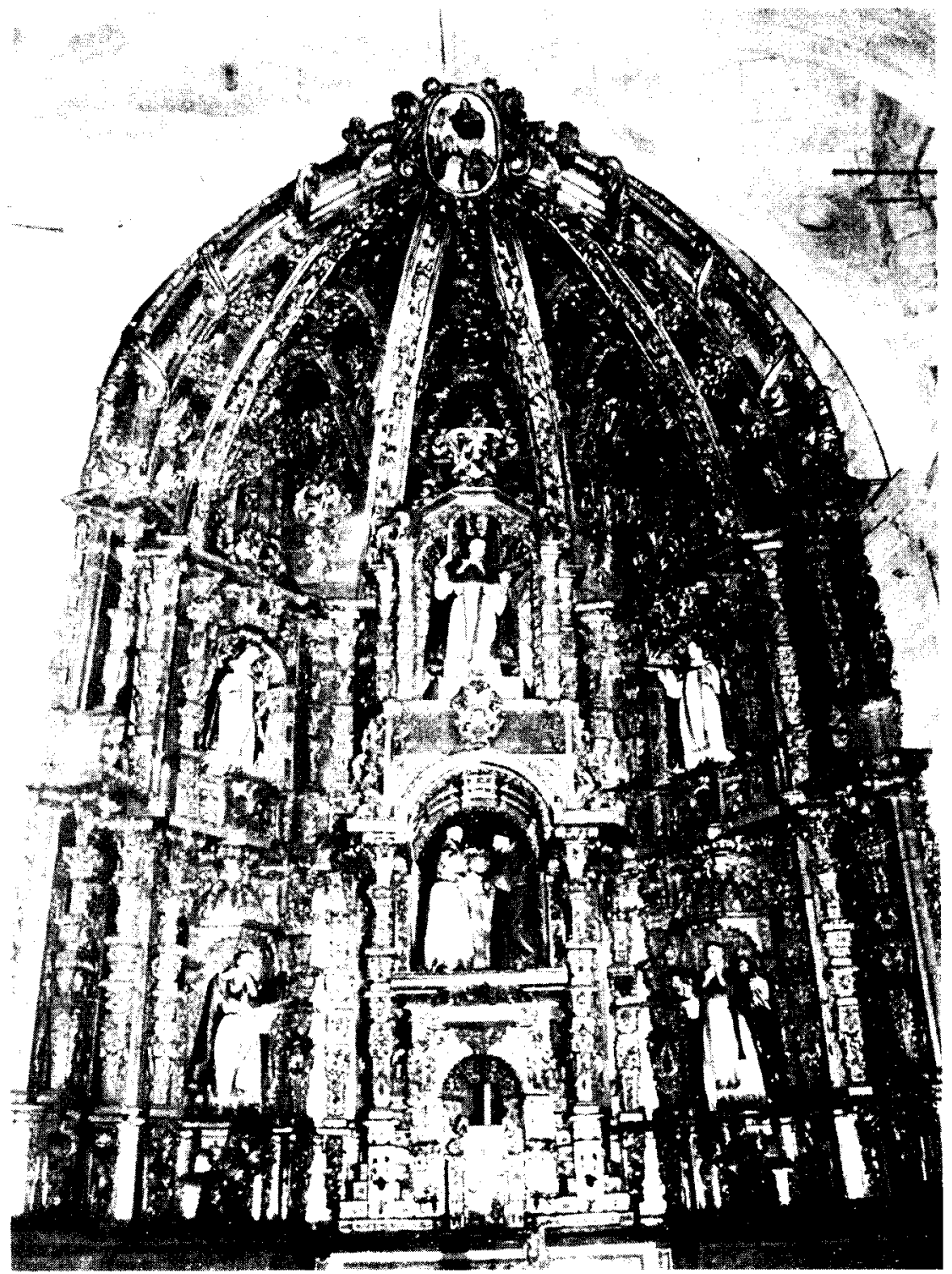

Fig. 4. Santo Domingo de Tui 


\section{Datos sobre su construcción}

El 11 de abril de 1744 se protocoliza el contrato entre la comunidad de Santo Domingo y Antonio del Villar con un condicionado muy explicito:

"... que dho Villar ha de hazer el retablo para la capilla Mayor de la Yglesia de estte dho Convento, segun el diseño y planta que presenta, delineada devajo regla de Arquitecttura, que se compone de ttres cuerpos, el primero horden Corinttia, el segundo horden Compositta, el ttercero bestido los quatro rampantes, que ha de rremattar en la clave de medio adornado con sus luces, y lo que el Artte diere mejor de si para su adorno; $Y$ en los dos cuerpos referidos se ha de adornar el deligneado que enseña dho diseño $y$ planta con la talla correspondiente a sus estipittes y las caxas donde han de enttrar seys esttattuas de a ocho quartas correspondientes a dha obra y el mencionado diseño se compone de ttres ochavas, la de medio ha de ttener de salida diez quartas para en ella formar custtodia para recivir a otro Amo y Señor Sacramenttado en publico. Ademas prosiguiendo el camarin con tres gradas para recivir a ntro Padre y Patriarca santo Domingo y que alli se pueda colocar el Juebes Santo el Monumento sin que aya menester de ottra $\cos a \ldots$

El coste ascendió a 17.500 reales de vellón, pagados en tres plazos: 4.000 rls. al principio; 6.000 en midad de la obra y los 7.500 restantes una vez terminada. Se le darían todos los materiales, madera, estadas, hierro, cola y plomo y además celda, cama, de comer y beber en el convento mientras durase la obra.

Aunque no se le señalaba un plazo de tiempo determinado, sí se fijaba una fecha de comienzo, para siete meses después y «... proseguir en ella sin ynterpelacion de otra astta concluida".

Pasaron 32 años, hasta que la comunidad se decidió a dorar el retablo. Se fecha la escritura de remate para esta operación el 2 de marzo de 1775 y serán los portugueses Manuel da Silva y Josef Duarte Carvallo, ambos de la ciudad de Braga, quienes se encarguen de la obra por 14.500 reales de vellón bajo las condiciones siguientes:

"La primera que hande dorar el mar/co del frontal q ttiene el altar maior = que han de labar los nichos de santto Thomas, / y san Jazinto, y' enseguida borberlos a dorar = tercera que asimismo han de dorar/las pinturas que tienen en los nichos sta Rosa y Sra Catthalina = quarta que/ han de registrar la custodia de dho Altar malor, y siempre que no se halle firme el oro/ que ttiene, por dentro, $y$ por fuera se lo han de dar de nuebo, y componerla enteramentel como tanbien los pedacittos de que se alla faltosa, por averle caido = quinta tambien han/ de registrar la preparacion de la caja de San The/mo, y siempre queno este segura le/ han de labar, y prepararla de nuebo: sesta que todo lo demas del retablo se ha de pin'ttar a oro y bronzeado a donde 
conbenga; todo ello de buena y mejor calidad dado con todo/ aseo segun lo permita su arte; septima que las maderas esttadas, jornales, cla/vazon, y mas que se necesite seran de quenta de los Maestros y no del ottorgantte, $y$ ' su Comunidad, que solo tendra cumplido con aprontar los dhos cattorze mil, y/ quinientos rrs en la forma quese dira = octava: que siempre y quando que dhol padre Prior, su Comuinidad, oqualquiera de los Religiosos e individuos nottaren alguna/ imperfecion, y falta de solides en los materiales, y forma de obrar, que sera de quenta de/ los Maestros azerle de nuebo o en defecto dha comunidad podra executarlo a costa de/ los efectos de este ajuste, con otros Maestros de su sattisfacion: nona; que han/ de dar dho rettablo dorado en los primeros seis meses siguientes al presente, bajo/ la expresa condicion de que no aziendolo ansi sea de su quentta las quiebras, daños y mas/perjuicios que a la Comunidad se siga, los que sera visto desconttarles de la canttidad principall La decima y ultima condicion de que dhos cattorce mil y quinientos rrs vllon no se los han de pagar astta que ttengan fenezido entteramente la pinttura, $y$ doracion de dho retablo, sus nichos/ tallas, y moldura, y que estto sea reconozido a costta de esttos Maestros, con ottros del arte/ inparciales que declaren bajo jura/mento consttruida la obra, segun buen arte."

Fuentes documentales y bibliográficas

A.C.T., esno. Juan García de Soto. Prot. T. (92), fol. 45.

A.C.T., esno. Antonio Gil de Otero, Prot. 1776, fol 30.

IGLESIAS ALMEIDA, Ernesto. op. cit. pág. 155-157; 229-231.

COUSELO BOUZAS, Galicia artistica en el s. xvin y primer tercio del s. XIX, pág. 653.

RETABLO MAYOR DEL CONVENTO DE LA DOMINICAS DE BAIONA. 1745. MIÑOR

\section{Descripción}

No cubre enteramente el muro del testero, ni se adapta a la bóveda encasetada que forma la cubierta de la capilla mayor.

De planta cóncava, presenta un zócalo (sotobanco) de madera con talla vegetal y angelillos en los laterales, sobre el que se asienta el retablo.

Lo primero que destaca es el magnífico sagrario-expositor integrado en un armónico conjunto de tres piezas, que se disponen de la siguiente manera: el receptor de la Eucaristía, (con un relieve del Buen Pastor en la puertecilla), una pequeña hornacina avenerada, con diseño de pequeño 
arco triunfal, que sirve también de pedestal al expositor, abierto a tres frentes con cúpula gallonada, como remate, que cobija el grupo escultórico de la Anunciación. Como soportes utiliza estípites.

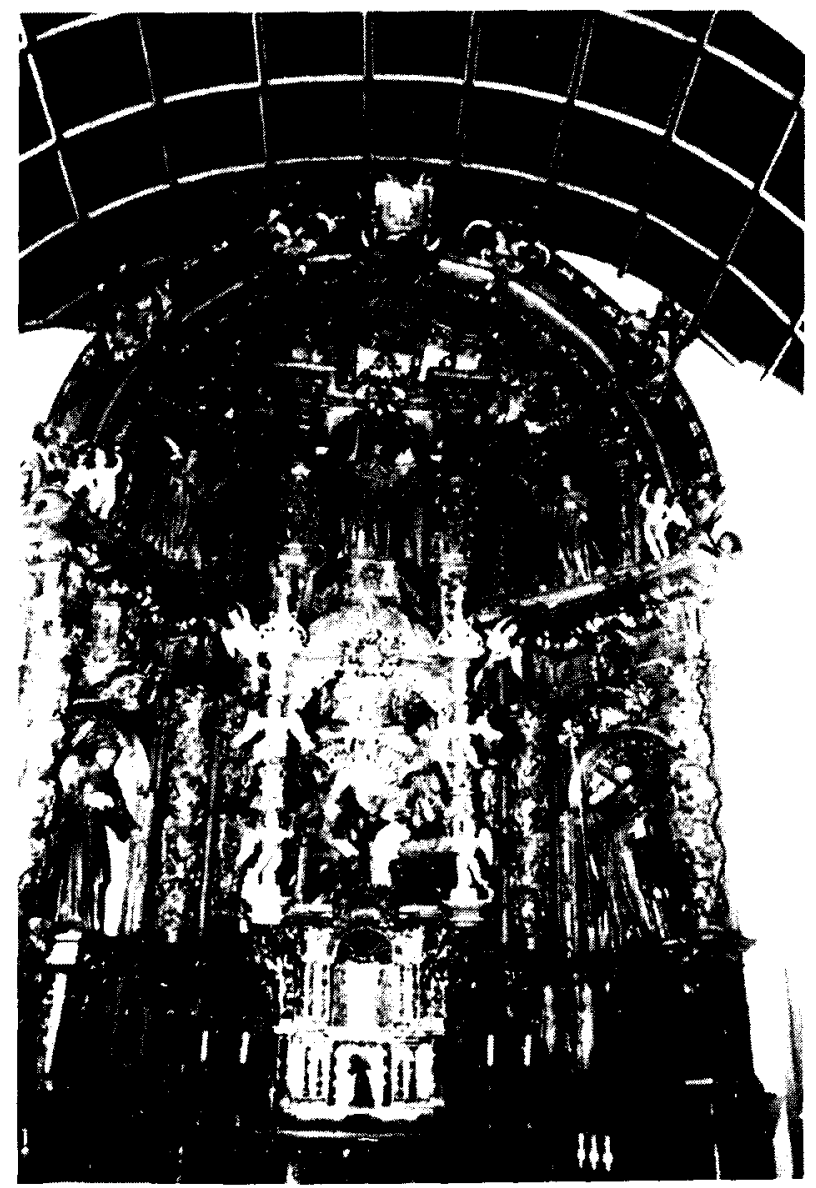

Fig. 6. Dominicas de Baiona

En las calles laterales se abren sendas hornacinas de arco de medio punto rematados en tarjetas de doble concha con hojas canescas. Reciben las esculturas de Santo Domingo y San Francisco. La división de las mismas se efectúa por medio de columnas salomónicas, densamente ornamentadas con rameados, flores y frutos.

El entablamento que sólo permanece en los fragmentos correspondientes a las calles laterales, presenta claramente sus tres partes clásicas y se decora con ovas. 
El ático reparte su espacio en tres cajas de similares proporciones, con entablamentos independientes, aunque resaltada la central (como es habitual) por estípites que la flanquean con los apoyos destacados y los capiteles recubiertos por una cornisa que presenta mayor vuelo que las laterales. Las tres se rematan igualmente por cartelas y reciben las imágenes de San Telmo, Santo Tomás y Santa Catalina de Siena.

El retablo cierra en semicírculo con escudo en la clave y cartelas intermitentes distribuidas por su recorrido.

\section{Datos sobre su construcción}

El 6 de junio de 1745 se protocoliza el contrato entre las religiosas del convento de Santo Domingo y Antonio del Villar;

"... y dijeron que haviendose determinado por la comunidad deeste conbento el hazer rettablo en el Alttar maior de la iglesia del acausa de amenazart ruina el que tiene y ser Indezente por lo antiguo que hes, fijaron zedulas para que con/currieren maestros escultores ahazer postturas enbiando asimismo abisos/ a diferentes partes para que concurriesen aeste efecto los quequisieren, señalan/dose como reseñado su rematte para oy dia de la fecha y aunque algunos maestros/ hanconcurrido con planttas para lattal obra y su postura ninguna fue mas conformel ni de menor quanttia quela del referido Antonio del Villar que la hizo en diezl mil rls de vellon con las condisiones siguientes: que dho rettablo ha de ser are/glado al alzado que enseña el diseño y suplanttado que ba firmado delos otor/gantes con las Ymagenes señaladas en sus guecos y los Angeles que le corres/pondan asu ornamento y remates con el Abanzamiento del cascaron dela serchal todo ello de madera castaño seca y vien acondisionada y el altto y ancho/ correspondiente al diseño y campo que enseña dho alttar mayor, oculpando todo el trente de alto avajo".

\section{Debería estar terminado en marzo del año siguiente de 1746.}

No esperaron demasiado las religiosas para dorar el retablo pues el 17 de abril de 1748 formalizan el contrato con el pintor Juan del Rial vecino de San Mamed de Priegue:

"... e dixeron que por quanto antes deaora se han' echo y se hallan fixadas el rretablo del altar dela capilla malor que tiene la/ Yglesia de dho convento y los dos colaterales della en tuerza delas lizencias/ correspondientes por hallarense los antiguos yndezentes $y$ de ningun serviciol $y$ amenazando una total rruina que por lo mismo se vio prezisada dhai comunidad a mandarlos fabricar a sus expensas y siendo comoes igual/mente nezesa. rio el pintarlos y dorarlos como sehaze con otros de diver/sas Yglesias pues de este modo mueven mas bien a la devocion los corazo/nes de las xentes, 
suplicaron dhas Priora y Depositarias asu señoria el/ Ylustrisimo Señor Dn Joseph de Larumbe ovispo y señorl de la ciudad de Tuy se dignase conzederles lizencia para hazer y pintar dhos tres rretablos acosta por aora del caudal que dha Comunidad tiene/ prozedido de los prinzipios de las dotes $y$ servicio mandarlos entreotras/ cosas se pusiesen en publica postura y con efecto haviendose asi practica/do y fixado las zedulas necesarias, concurrido diversos pintores y echo/ cada uno las puxas o pusturas que vieron serles convenientes la mas yn/fima y mexor que ha havido fue la del dho Dn Juan del Rial pues ofreciol pintar y dorar los dhos rretablos y colaterales en forma segun las rre/glas de su arte por diez mil rrls de vellon en esta manera los ocho mill por el mismo rretablo maior y los dos mil por los denominados colaterales y por no haver havido otro pintor que lo executase por tanta ni menos/ cantidad le hubieron por echo el rremate por tanto en la mexor forma/ que aia lugar en derecho y este permite se obligan dhas Priora y Deposi/tarias con los expresados vienes rrentas y censos del nominado Conventol de pagar al dho Dn Juan del Rial los citados diez mil rreales de vellon' alguna porzion luego que comienze a travaxar en dha obra, otra en el/ medio della y la rrestante asi que la finalize".

\section{Fuentes documentales y bibliográficas}

A.H.P.P., esno. Alberto Velo y Collazo; Prot. 2.962 (3). Año 1745, fol. 21.

A.H.P.P., esno. Alberto Velo y Collazo; Prot. 2.962 (6). Año 1748, fol, 20.

\section{RETABLO MAYOR DE LA CAPILLA DE LA MISERICORDIA. BAIONA. MIÑOR}

\section{Descripción}

El retablo se articula por medio de banco que decora el apoyo de los soportes con ménsulas vegetales y los paneles laterales con motivos geométricos. La parte central la ocupa, como es de obligación, el sagrario, conformado por dos cuerpos de planta poligonal: el edículo para guardar el Santisimo y el expositor de tres frentes abiertos, fondo pintado con tupido follaje y rematado por un cuarto de cascarón. Tanto uno como el otro llevan estípites, adosados en el inferior, exentos en el superior y machones en los laterales.

La calle central, de mayor amplitud, se ocupa con una hornacina de tres frentes abiertos y combinando salomónicas con estípites. Guarda en su interior la escena del Calvario, la imagen del Crucificado sobrepuesto a un lienzo en el que aparecen pintadas las figuras de la Virgen y San Juan Evangelista en un fondo neutro. 


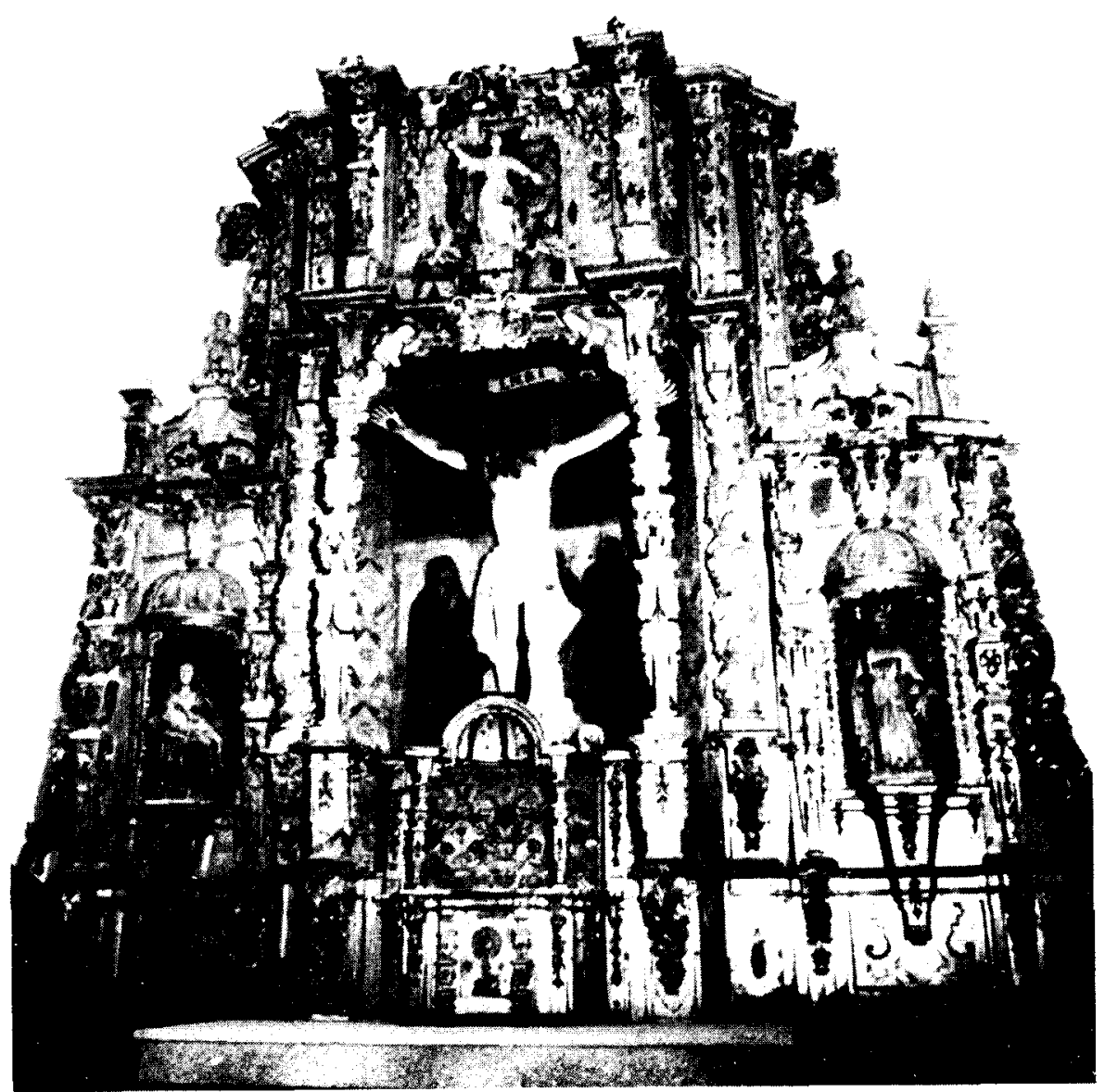

Fig. 7. Casa Misericordia de Baiona 
En las calles laterales, delimitadas por estípites se abren sendas hornacinas que acogen a Santa Isabel de Portugal y una Piedad colocadas sobre peanas troncopiramidales. Rematan las cajas, bovedillas de un cuarto de esfera gallonadas.

La cornisa del entablamento, decorada en su base con ovas, forma un rectángulo en su centro, al quebrarse hacia arriba, para proporcionar a la calle central mayor holgura, constituyendo así la ruptura de este elemento, en su esencia, horizontal.

El ático que adquiere forma rectangular, muestra una caja con la imagen de la Asunción, con pilastrillas, estipites y machones sucediéndose a ambos lados, hasta acabar en aletones que le ponen en contacto con los remates extremos, en forma piramidal, que ostentan un angelillo en el vértice y pináculos laterales.

Aunque no disponemos de la documentación perteneciente a este retablo, reconocemos en él elementos característicos del modo de hacer del retablista que nos ocupa; como son las peanas del primer cuerpo que ya utilizó en el retablo de las Madres Dominicas; el mismo diseño de hornacina con el remate que sube desde la clave a la cornisa, que vimos en Santa María de Reboreda y el sagrario que es similar a los demás retablos documentados. Su mano aparece claramente.

Si además añadimos a estos detalles estilísticos, la situación geográfica de este ejemplar, en la villa de Baiona, donde el maestro trabajó activamente, no nos parece descabellada esta atribución.

Es preciso mencionar finalmente que, en esta obra, combina los motivos vegetales con lazos y otros esquemáticos y geométricos que empleara ya en el de Santa Liberata. 
, 